\title{
Gel-tape-casting of aluminum nitride ceramics
}

\author{
Qiushun SHANG ${ }^{a, b}$, Zhengjuan $\mathrm{WANG}^{a}$, Jun $\mathrm{LI}^{a,{ }^{*}}$, Guohong ZHOU ${ }^{a}$, \\ Hailong ZHANG ${ }^{a}$, Shiwei $\mathrm{WANG}^{a,{ }^{*}}$ \\ ${ }^{a}$ State Key Laboratory of High Performance Ceramics and Superfine Microstructure, \\ Shanghai Institute of Ceramics, Chinese Academy of Sciences, Shanghai 200050, China \\ ${ }^{b}$ University of Chinese Academy of Sciences, Beijing 100049, China
}

Received: May 21, 2016; Revised: September 27, 2016; Accepted: October 15, 2016

C The Author(s) 2016. This article is published with open access at Springerlink.com

\begin{abstract}
Aluminum nitride ceramic sheets were formed for the first time by a novel and simple method, namely gel-tape-casting process, where only two additives were used to prepare the slurries. PIBM (a water-soluble copolymer of isobutylene and maleic anhydride) acted as both dispersant and gelling agent, and PEG (polyethylene glycol) acted as plasticizer. Combining the advantages of gel-casting and tape-casting processes, flexible and uniform green tapes were obtained. The rheological properties of AIN slurries were studied to optimize the PIBM content and solids loading. After drying and debinding, the green sheets were sintered at $1840{ }^{\circ} \mathrm{C}$ in $\mathrm{N}_{2}$ atmosphere. Homogeneous microstructure with average grain size of about $7 \mu \mathrm{m}$ was observed in the final AlN ceramics. Thermal conductivity of the AlN ceramics was $161 \mathrm{~W} /(\mathrm{m} \cdot \mathrm{K})$.
\end{abstract}

Keywords: AlN ceramic sheets; gel-tape-casting; PIBM; rheological properties; microstructure

\section{Introduction}

With high thermal conductivity [1], high electrical resistance, and low dielectric property, aluminum nitride has been considered as the most promising material for substrates, especially for high power circuitry in microelectronics field. Generally, high quality thin AlN ceramic substrates for electronic applications are fabricated by tape-casting process [2]. There are two types of tape-casting process based on different kinds of solvents, non-aqueous and aqueous systems [3,4]. For the non-aqueous system, organic additives are flammable and toxic, which would cause environmental problems. As more and more attention is paid on environment protection, researchers are trying

* Corresponding authors.

E-mail: J. Li, leejimmy@mail.sic.ac.cn;

S.Wang, swwang51@mail.sic.ac.cn to find ways to replace those organics. As a result, the aqueous system was developed, which is incombustible, non-toxic, and environmentally friendly.

Up to now, reports on aqueous tape-casting of AlN were rare. As hydrolysis would occur when AlN powder was dispersed in water, surface modification was needed for AlN powder. In 2004, Luo et al. [5] used DP270 as both dispersant and hydrolysis inhibitor to prepare AlN green sheets by aqueous tape-casting. In 2005, Olhero and Ferreira [6] prepared water-based AlN slurries by adding $\mathrm{H}_{3} \mathrm{PO}_{4}$ as a protective agent against hydrolysis. Binders and dispersants are also needed in aqueous tape-casting, and the addition contents are always very high, which would also cause environmental problems in the debinding process.

On the other hand, due to the migration of the solvents, inhomogeneous microstructure would form along the thickness of the tape, which makes it impossible to prepare thick sheets. Thus, a complicated 
method combining stack and WIP (warm isostatic pressing) was used to make thick sheets. Gel-casting is a near-net shaping method for ceramic forming with complex shapes [7], which is suitable for preparing bulk ceramics without forming inhomogeneous microstructure. In 2002, Xiang et al. [8] developed a novel method called gel-tape-casting to produce alumina sheets. It combined tape-casting with gel-casting technology which is based on free radical polymerization. However, five kinds of additives were used: dispersant, monomer, cross-linking agent, catalyst, and initiator. In addition, plasticizer was added to improve the flexibility of green tapes. Except for the multiple additives, there was an anti-polymerizing effect of oxygen, which made the process complicated. In 2004, a novel gel-tape-casting process using sodium alginate was reported [9]. Sodium alginate was dissolved in water at room temperature and formed a three-dimensional network in the presence of multivalent cations. Styrene-acrylic latex was used to improve the flexibility of green tapes. Gelation rate could be controlled by the amounts of adipic acid and sequestrant. Green tapes with homogeneous microstructure were fabricated by this process. In 2014, a new system in shaping techniques by in situ polymerization was reported. Instead of commonly applied 2-hydroxyethyl acrylate or acrylamide (monomer) and $\mathrm{N}, \mathrm{N}, \mathrm{N}^{\prime}, \mathrm{N}^{\prime}$-tetramethylethylenedia mine (activator), 3-O-acryloyl-D-glucose and Lascorbic acid were used as monomer and activator, respectively [10]. The new system based on non-toxic glucose derivatives has been described in detail, and it allowed to form defect free tapes and dense sintered bodies by gel-tape-casting.

In 2013, Yang et al. [11] developed a simple method for gel-casting of alumina ceramics using a non-toxic and water-soluble copolymer of isobutylene and maleic anhydride (simply noted as PIBM). It only needed small amount of PIBM $(0.3 \mathrm{wt} \%)$ which acted as both dispersant and gelling agent for gel-casting of ceramics. Also, oxygen inhibition would not occur in this system. Then in 2014, Shu et al. [12] fabricated AlN ceramics with a fin-like shape by gel-casting process with addition of PIBM. These studies show that PIBM would be a better choice for preparing slurries, which make it easier for fabricating complicated and large-size ceramics.

In this study, tape-casting and the simple novel gel-casting process using PIBM were combined to obtain flexible and uniform aluminum nitride ceramic green tapes. Only small amounts of additives were added. Finally, dense AlN ceramic sheets were fabricated by pressureless sintering at $1840{ }^{\circ} \mathrm{C}$ for $4 \mathrm{~h}$ in $\mathrm{N}_{2}$ atmosphere.

\section{Experimental procedure}

Commercial AlN powder (Grand F, Tokuyama Co., Japan) with an average particle size of $1.1 \mu \mathrm{m}$ was used as raw material, and the density was $3.26 \mathrm{~g} / \mathrm{cm}^{3} . \mathrm{Y}_{2} \mathrm{O}_{3}$ was used as sintering aid [13], and its average particle size and density was $2.0 \mu \mathrm{m}$ and $5.01 \mathrm{~g} / \mathrm{cm}^{3}$, respectively. Because of the hydrolysis of these two kinds of powder [14], they were coated with a waterproof agent. The waterproof agent is a commercial waterproof material, whose main component is polyurethane. AlN, $\mathrm{Y}_{2} \mathrm{O}_{3}$, and the waterproof agent were mixed in alcohol for $2 \mathrm{~h}$, and then the mixed slurry was dried at $50{ }^{\circ} \mathrm{C}$. PIBM with an average molecular weight of 160 000-170 000 (ISOBAM 110\#, Kuraray, Osaka, Japan) was used as both dispersant and gelling agent [11], and its molecular structure is shown in Fig. 1. Polyethylene glycol (PEG600) was used as plasticizer.

The experimental process of gel-tape-casting is shown in Fig. 2. First, PIBM solution was prepared, and the coated AlN and $\mathrm{Y}_{2} \mathrm{O}_{3}$ ( $3 \mathrm{wt} \%$ with respect to $\mathrm{AlN}$ )<smiles>CC(C)(C)CC(C(N)=O)C(C([NH3+])=O)C(C)(C)CC1C(=O)OC(=O)C1F</smiles>

Fig. 1 Molecular structure of PIBM.

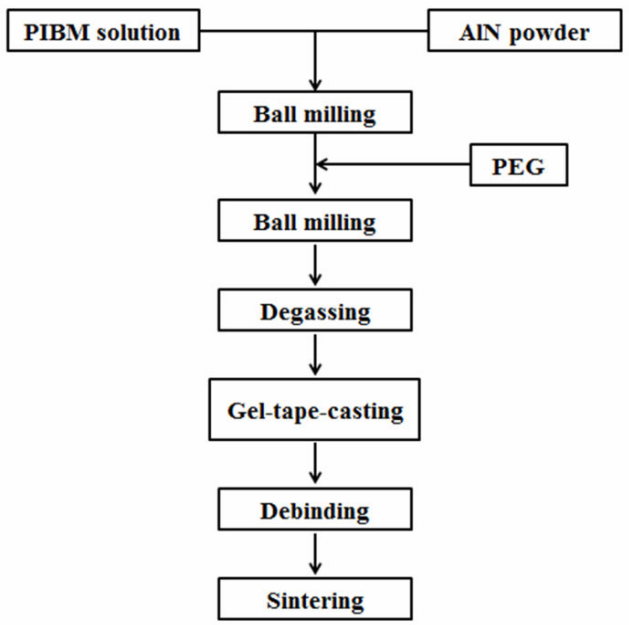

Fig. 2 Flowchart of the gel-tape-casting process. 
powder and PEG600 (5 wt\% with respect to AIN) were added into the solution to make the slurry. Then, ball milling was used $(200 \mathrm{rpm}, 4 \mathrm{~h})$ to make the slurry well-distributed. The slurry was degassed $(1000 \mathrm{rpm}$, $0.05 \mathrm{~atm}, 30 \mathrm{~s}$ ) by THINKY MIXER ARV0-310. Then, the slurry was poured into the reservoir and tape-casted in air with a doctor blade of $20 \mathrm{~cm}$ in width to get the green tapes. After demolding and debinding, the green sheets were sintered at $1840{ }^{\circ} \mathrm{C}$ for $4 \mathrm{~h}$ in $\mathrm{N}_{2}$ atmosphere.

Rheological behavior was characterized with a stress-controlled rheometer (Physica MCR301, Anton Paar, Graz, Austria) with a parallel plate $(25 \mathrm{~mm}$ in diameter). The viscosities of the slurries were measured with the continuous shear mode increasing from 1 to $1000 \mathrm{~s}^{-1}$ at $25{ }^{\circ} \mathrm{C}$. Microstructure and energy dispersive spectrum (EDS) test were carried out by scanning electron microscopy (SEM, JSM-6390, JEOL, Japan) and field emission scanning electron microscopy (FESEM, GeminiSEM 500, Zeiss, Germany). Thermal diffusivity was measured by laser-flash method. The density of AlN ceramics was measured by the Archimedes method in distilled water.

\section{Results and discussion}

\section{1 Rheological properties of AIN slurries}

High solids loading, good fluidity, and stability are expected for both tape-casting and gel-casting, so they are also important in the slurries for gel-tape-casting. For typical slurries, the rheological behavior is influenced by ceramic powder, solvent, solids loading, dispersant, binder, and other organic additives, and the content of binder is the most important factor [3]. PIBM is a copolymer of isobutylene and maleic anhydride, so it can act as dispersant as well as binder in slurries. Rheological behaviors of the slurries with different binder content and solids loading were investigated.

\section{1.1 Viscosity of AlN slurries varying with binder addition}

Rheological properties of the slurries with different PIBM concentration are shown in Fig. 3. The solids loading of the slurries was fixed to $38 \mathrm{vol} \%$ and the PIBM addition was in the range of $2-4 \mathrm{wt} \%$ (powder-based) at room temperature. The slurry compositions are listed in Table 1. It is clear that all slurries show a shear-thinning character with increasing

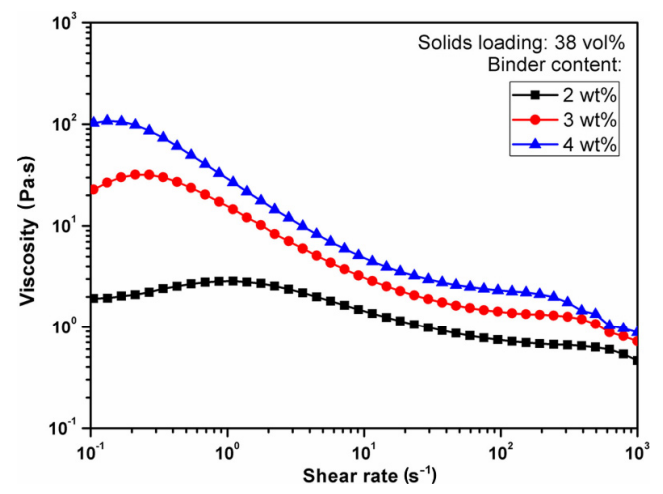

Fig. 3 Viscosity of AlN slurries with different PIBM content (solids loading: $38 \mathrm{vol} \%$ ).

Table 1 Composition of AIN slurries with different PIBM addition and solids loading

\begin{tabular}{ccc}
\hline No. & $\begin{array}{c}\text { Solids loading } \\
(\text { vol } \%)\end{array}$ & $\begin{array}{c}\text { PIBM (wt } \% \text { of } \\
\text { AlN powder) }\end{array}$ \\
\hline 1 & 38 & 2 \\
2 & 38 & 3 \\
3 & 38 & 4 \\
4 & 40 & 3 \\
5 & 42 & 3 \\
\hline
\end{tabular}

shear rate. In addition, the viscosity increases with increasing PIBM content from 2 to $4 \mathrm{wt} \%$. When the addition content of PIBM increases from 3 to $4 \mathrm{wt} \%$, there is little change in the viscosity of the slurries. While, for lower content ( $2 \mathrm{wt} \%)$, the strength of green tape is poor and it is difficult to get an intact green tape off the carrier. Therefore, $3 \mathrm{wt} \%$ PIBM content was chosen for the gel-tape-casting and demolding process.

\section{1. 2 Viscosity of AlN slurries varying with solids loading}

Figure 4 shows the viscosity of slurries as a function of solids loading and $3 \mathrm{wt} \%$ PIBM. The compositions of the slurries are listed in Table 1, and the solids loading is varied from 38 to $42 \mathrm{vol} \%$. It could be found that all the slurries show a shear-thinning behavior. The two curves of slurries with solids loading of 38 and $40 \mathrm{vol} \%$ are very close. And the viscosity increases significantly when the solids loading increases up to $42 \mathrm{vol} \%$. It is important to obtain stable and homogeneous slurry with low viscosity and high solids loading, whereas higher solids loading can result in high viscosity and inhomogeneous slurry. As we can see, the slurry with a solids loading of $40 \mathrm{vol} \%$ has proper viscosity and relatively high solids loading. From Fig. 3 and Fig. 4, the slurry with $40 \mathrm{vol} \%$ solids loading and $3 \mathrm{wt} \%$ PIBM has the best performance, so they are the optimal conditions for the gel-tape-casting process. 


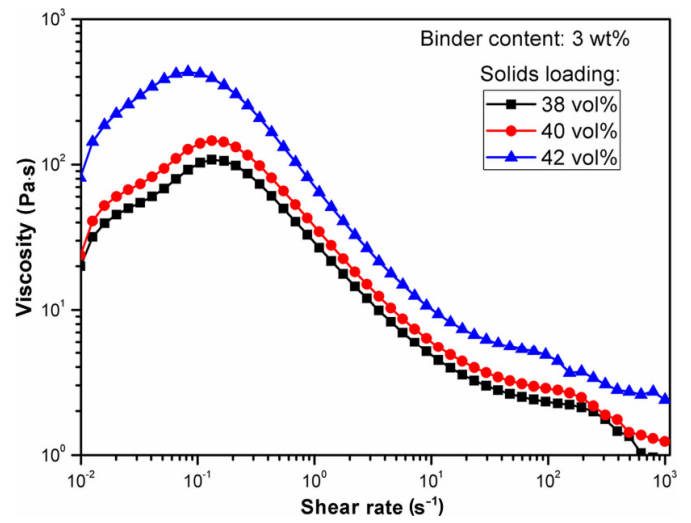

Fig. 4 Viscosity of AlN slurries with different solids loading (PIBM addition: $3 \mathrm{wt} \%$ ).

\section{2 Effect of plasticizer on storage modulus}

In traditional gel-casting system, there is no plasticizer. Thus, after casting and drying, the green body is hard and brittle. In the gel-tape-casting process, in order to obtain flexible green tape, plasticizer was used. The storage modulus is often used for the characterization of gelation rate. As shown in Fig. 5, without the plasticizer, the slurry shows a high storage modulus at the start point and an increased storage modulus behavior with time going, which is similar to the normal gel-casting process. After the addition of plasticizer, the curve shows a similar tendency, but the value of storage modulus is much smaller. In other words, the plasticizer greatly prolongs the curing time, and after drying, the green body is flexible instead of hard and brittle.

\section{3 Characterization of AIN green tapes}

With the addition of appropriate amount of plasticizer, flexible tapes were obtained and shown in Fig. 6(a), and the thickness of the tapes was between 250 and $550 \mu \mathrm{m}$. The green tapes produced from slurry with solids loading of $40 \mathrm{vol} \%$ and binder addition of $3 \mathrm{wt} \%$ were

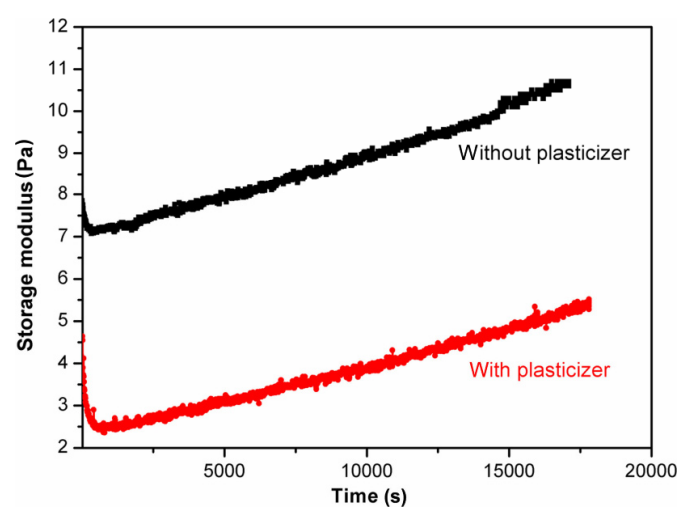

Fig. 5 Effect of plasticizer on the evolution of storage modulus $G^{\prime}$ of slurries with a solids loading of $40 \mathrm{vol} \%$.
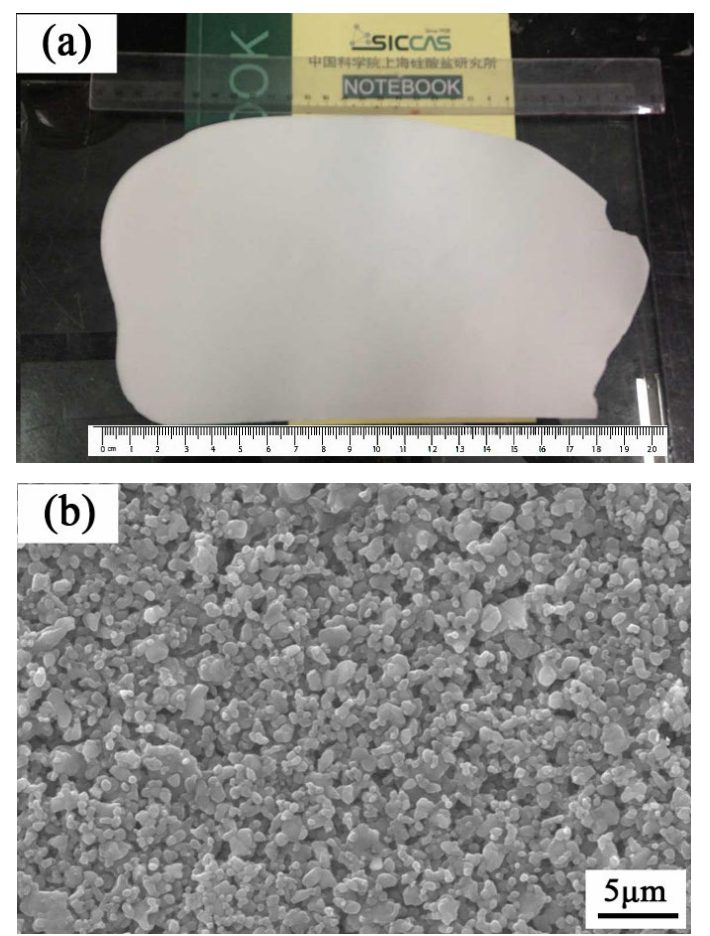

Fig. 6 (a) Photograph and (b) microstructure of AlN green tape after casting in air at room temperature.

smooth, uniform, and without cracks. The microstructure of the green tapes is shown in Fig. 6(b). It can be seen that the AlN particles are homogeneously distributed and there are no obvious defects. All the organic additives were burned out by the debinding process, with temperature up to $500{ }^{\circ} \mathrm{C}$.

\section{4 Properties of dense AIN ceramics}

Dense AlN ceramics were obtained by pressureless sintering at $1840{ }^{\circ} \mathrm{C}$ for $4 \mathrm{~h}$ in $\mathrm{N}_{2}$, as shown in Fig. 7 . The average grain size is about $7 \mu \mathrm{m}$, and no visible pores or defects are observed. However, second phases can be clearly seen on the grain boundaries. EDS test was carried out to determine the composition of the second phases. Figure 8 shows the EDS mapping results of the fracture surface of the ceramics. Obviously, Y and $\mathrm{O}$ elements are distributed on the grain boundaries. As the sintering temperature is high, $\mathrm{Y}_{2} \mathrm{O}_{3}$ and $\mathrm{AlN}$ can react with each other, so compounds with $\mathrm{Y}, \mathrm{Al}, \mathrm{O}$, and $\mathrm{Y}_{2} \mathrm{O}_{3}$ can be the second phases. Spot scanning of the second phases also shows that $\mathrm{Al}, \mathrm{Y}$, and $\mathrm{O}$ elements are distributed. The composition of the second phases and their distribution would affect the thermal conductivity of AlN ceramics [15].

The density of the AlN ceramics was determined by the Archimedes method, which is $3.3 \mathrm{~g} / \mathrm{cm}^{3}$. Thermal diffusivity was measured by the laser-flash method. The 


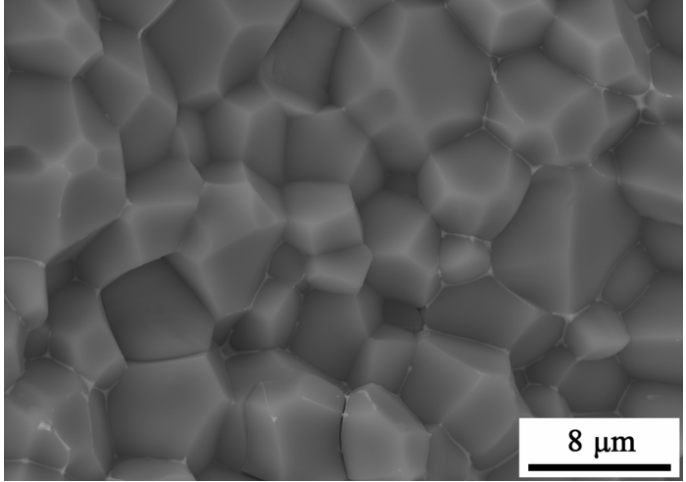

Fig. 7 Microstructure of the dense AlN ceramic fracture (backscattered electron image).
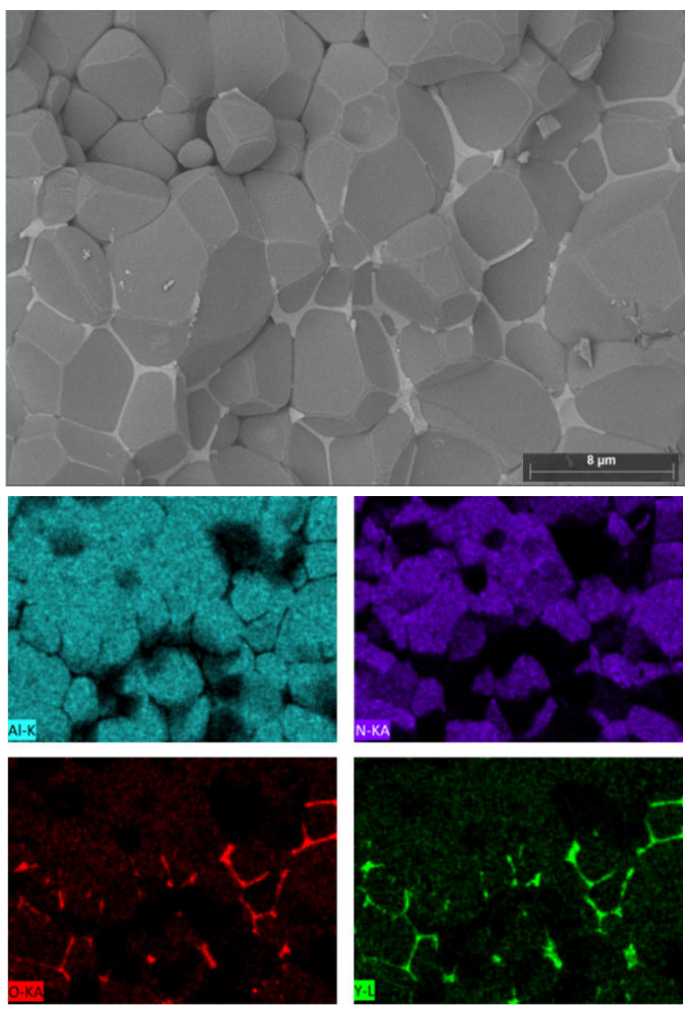

Fig. 8 EDS mapping of the AIN ceramics on fracture surface.

thermal conductivity of the ceramics is determined from the following formula:

$$
\lambda=\alpha \cdot \rho \cdot C_{p}
$$

where $\alpha$ is the thermal diffusivity $\left(\mathrm{cm}^{2} / \mathrm{s}\right), \rho$ is the density $\left(\mathrm{g} / \mathrm{cm}^{3}\right)$, and $C_{p}$ is the heat capacity of the material $(\mathrm{J} /(\mathrm{g} \cdot \mathrm{K}))$. The tested thermal diffusivity is $0.66284 \mathrm{~cm}^{2} / \mathrm{s}$. The heat capacity of pure, dense AlN $\left(0.734 \mathrm{~J} /(\mathrm{g} \cdot \mathrm{K})\right.$ at $\left.20{ }^{\circ} \mathrm{C}\right)$ was used to calculate thermal conductivity of the AlN ceramics and it is $161 \mathrm{~W} /(\mathrm{m} \cdot \mathrm{K})$. It is lower than the reported one $(204 \mathrm{~W} /(\mathrm{m} \cdot \mathrm{K})$ in Ref. [12]). As we know, the thermal conductivity of AlN ceramics is affected by the low thermal conductive second phases segregated in grain boundary, including the morphology and microstructure of the second phases [16]. From the microstructure and EDS analysis (Figs. 7 and 8), the second phases are connected to each other, which would decrease the thermal conductivity of the AlN sheet to a large extent. By changing the morphology of the second phases into isolated structures, it can improve the thermal conductivity. On the other hand, as the distribution of the second phases is not uniform in the ceramics, it can be inferred that the waterproof agent does not play an effective role. This would lead to inhomogeneous hydrolysis of AlN and $\mathrm{Y}_{2} \mathrm{O}_{3}$ in the slurries and increase the generation of second phases. Further study will be carried out to solve these problems and improve the thermal conductivity of the AlN ceramic sheet.

\section{Conclusions}

A simple gel-tape-casting method was used to prepare AlN ceramic sheets. A copolymer PIBM was employed as both dispersant and gelling agent, and PEG was used as plasticizer. With the addition of $3 \mathrm{wt} \%$ PIBM and a solids loading of $40 \mathrm{vol} \%$, the aqueous slurries showed the best performance and flexible green tapes were obtained. After the debinding and pressureless sintering, dense AlN sheets with an average grain size of about $7 \mu \mathrm{m}$ and no big pores or other defects were obtained. Thermal conductivity of the prepared AIN sheets reached $161 \mathrm{~W} /(\mathrm{m} \cdot \mathrm{K})$. The results showed that PIBM is an effective and environmentally friendly additive for gel-tape-casting of AIN ceramic sheets, and the effective control of the composition and distribution of the second phases will improve the properties of the AlN sheets.

\section{References}

[1] Slack GA, Tanzilli RA, Pohl RO, et al. The intrinsic thermal conductivity of AlN. J Phys Chem Solids 1987, 48: 641-647.

[2] Mistler RE. Tape casting: The basic process for meeting the needs of the electronics industry. Am Ceram Soc Bull 1990, 69: 1022-1026.

[3] Hotza D, Greil P. Review: Aqueous tape casting of ceramic powders. Mat Sci Eng A 1995, 202: 206-217.

[4] Descamps M, Moreau G, Mascart M, et al. Processing of aluminum nitride powder by the tape-casting process. $J$ Eur Ceram Soc 1994, 13: 221-228. 
[5] Luo X-J, Zhang B-L, Li W-L, et al. Preparation of aluminum nitride green sheets by aqueous tape casting. Ceram Int 2004, 30: 2099-2103.

[6] Olhero SM, Ferreira JMF. Rheological characterisation of water-based AlN slurries for the tape casting process. $J$ Mater Process Tech 2005, 169: 206-213.

[7] Young AC, Omatete OO, Janney MA, et al. Gelcasting of alumina. J Am Ceram Soc 1991, 74: 612-618.

[8] Xiang J, Xie Z, Huang Y. Processing of $\mathrm{Al}_{2} \mathrm{O}_{3}$ sheets by the gel-tape-casting process. Ceram Int 2002, 28: 17-22.

[9] Yu Z, Huang Y, Wang C, et al. A novel gel tap casting process based on gelation of sodium alginate. Ceram Int 2004, 30: 503-507.

[10] Wiecinska P, Graule T, Szafran M. L-Ascorbic acid as a new activator in fabrication of ceramics by techniques using in situ polymerization. J Eur Ceram Soc 2014, 34: 1581-1589.

[11] Yang Y, Shimai S, Wang S. Room-temperature gelcasting of alumina with a water-soluble copolymer. J Mater Res 2013, 28: 1512-1516.

[12] Shu X, Li J, Zhang H-L, et al. Gelcasting of aluminum nitride using a water-soluble copolymer. J Inorg Mater 2014, 29: 327-330.
[13] Jackson TB, Virkar AV, More KL, et al. High-thermalconductivity aluminum nitride ceramics: The effect of thermodynamic, kinetic, and microstructural factors. $\mathrm{J} \mathrm{Am}$ Ceram Soc 1997, 80: 1421-1435.

[14] Fukumoto S, Hookabe T, Tsubakino H. Hydrolysis behavior of aluminum nitride in various solutions. $J$ Mater Sci 2000, 35: 2743-2748.

[15] Yan H, Cannon WR, Shanefield DJ. Evolution of carbon during burnout and sintering of tape-cast aluminum nitride. J Am Ceram Soc 1993, 76: 166-172.

[16] Lee HM, Bharathi K, Kim DK. Processing and characterization of aluminum nitride ceramics for high thermal conductivity. Adv Eng Mater 2014, 16: 655-669.

Open Access The articles published in this journal are distributed under the terms of the Creative Commons Attribution 4.0 International License (http://creativecommons. org/licenses/by/4.0/), which permits unrestricted use, distribution, and reproduction in any medium, provided you give appropriate credit to the original author(s) and the source, provide a link to the Creative Commons license, and indicate if changes were made. 